\title{
THE EFFECTS OF DOSAGES OF WORM AND NITROGEN- PHOSPHORUS FERTILIZERS ON PLANT GROWTH OF HYACINTHUS SP. IN SIIIRT PROVINCE, TURKEY
}

\author{
ALİ, S. R. - ÇIĞ, A.* \\ Department of Horticulture, Faculty of Agriculture, Siirt University, Siirt, Turkey \\ *Corresponding author: \\ e-mail: arzucig@yahoo.com; phone:+905316231533 \\ (Received 22 $2^{\text {nd }}$ Feb 2018; accepted 24 $4^{\text {th }}$ May 2018)
}

\begin{abstract}
This research was carried out in order to determine the effects of worm fertilizer and nitrogenphosphorus fertilizer dosage differences on flowering of hyacinth as a bulbous ornamental plant from 2016 to 2017 in Siirt University, Turkey. Solid worm fertilizer was applied at dosages of $25 \mathrm{~g} / \mathrm{bulb}$ (V1), $50 \mathrm{~g} / \mathrm{bulb}$ (V2), $75 \mathrm{~g} / \mathrm{bulb}$ (V3) and $2 \mathrm{~kg} /$ decare (NP1), $4 \mathrm{~kg} / \mathrm{dec}$ are (NP2), $8 \mathrm{~kg} /$ decare (NP3) NitrogenPhosphorus (NP) were applied during the growth of hyacinth (Hyacinthus orientalis L. cv. "Purple Star"). According to the results, the lowest (the earliest time) mean values of the first flowering time, full flowering time, and harvest time were obtained as 135.25 days, 136.54 days, and 137.70 days in V1 treatment, respectively. The highest mean value on leaf number $(5.71)$, leaf length $(128.21 \mathrm{~mm})$, stalk thickness $(13.50 \mathrm{~mm})$, and floret diameter $(28.14 \mathrm{~mm})$ were determined in $\mathrm{V} 1$. The highest mean values belong to flower diameter $(66.96 \mathrm{~mm})$ and length $(116.33 \mathrm{~mm})$ were evaluated in V2 and V3, respectively. Among NP fertilizers, in NP1 the highest mean value on floret number (37.69) while in NP2 the highest mean value on floret length $(26.76 \mathrm{~mm})$ were obtained. The highest mean values on leaf diameter and plant height were found as $28.86 \mathrm{~mm}$ and $179.54 \mathrm{~mm}$ in NP3 treatment. As a result, it has been determined that the hyacinth can be grown with worm fertilization without chemical fertilizer use under ecological conditions of Siirt province. Considering the adverse effects of chemical fertilizers on the environment, it is proved that there are no statistically significant differences between them and the worm fertilizer, which is a bio-fertilizer.
\end{abstract}

Keywords: chemical fertilizer, flowering, hyacinth, ornamental plant, plant growth, worm fertilizer

\section{Introduction}

Hyacinthus orientalis $\mathrm{L}$. is a herbaceous flower belonging to the hyacinth branch of the Liliaceae family species (Hu et al., 2015). This species was originally cultivated in the Mediterranean region and in South Africa (van Sheepen, 1991). In 1768, more than 2000 varieties of this species were recorded (Darlington et al., 1951). According to Shen et al. (2004), nowadays the common hyacinth cultivars used for gardening are Holland and Rome species (Hu et al., 2015). The genus of hyacinths consists of 30 species among which only $H$. orientalis have horticultural importance due to their longevity as cut flowers. As well as grown hyacinths are generally between 10 and 30 $\mathrm{cm}$ tall and come in a wide range of colors. The swollen portion consists mostly of fleshy, food storing scales attached to a short flat stem. The plants start flowering in the first part of February (Smigielska et al., 2014). The plant prefers moist but light sandy to loamy soils. These soils could be acidic, neutral or alkaline. The hyacinth is widely cultivated in pots and is used as a cut flower worldwide (Hu et al., 2015). Its fragrance and graceful style have provided this flower with considerable ornamental value. Also, many distinctive ornamental plant groups live in Turkey due to its location that is the cross- section point of Mediterranean, Europe-Siberia and Iranian-Turanian phytogeographical regions and because different climatic conditions prevalent in its 
region, which cause natural floristic richness, biological difference and several habitat characteristics which are unique. Flower cultivation, which has a large natural potential in Turkey, is gradually growing importance and become a productive agricultural and commercial branch. Cut flower cultivation is a development of ornamental plant production having the largest part either in production or economic value. Cut flower production includes the processes, where fresh or dried flowers or their parts are used in clamps and arrangements in their original or colored forms.

This study was formulated to investigate the potential role of bio-fertilizer application for enhancing growth, and flowering of Hyacinthus orientalis in a sustainable agricultural production system in order to reduce the amount of excessive chemical material released to the environment. The experiment was conducted with varying dosage of nitrogen-phosphorus (NP) and worm fertilizer (V) on Hyacinthus orientalis to find out the effects on criteria of growth and flowering of plants.

\section{Literature Review}

Activities such as growing, choosing, procession, classification, storing and marketing of flowers are included in the cut flower production process. Nearly 50 countries produce cut flowers. Turkey is among the most important countries having the largest potential for cut flower growing with its climatic and topographical characteristics (Sönmez et al., 2013). Generally, farmers use chemical fertilizers to improve soil fertility and hence increase the yield of their crops. However, the use of chemical fertilizers causes a great impact on the soil quality and the surrounding environment. Vermicomposting is a non-thermopiles and simple biotechnological process of composting, in which certain species of earthworms and microorganisms are used for biological degradation of organic waste (Arancon and Edwards, 2005; Khan and Ishaq, 2011). Sangwan et al. (2010) who inferred that soil amended with 30\% vermicompost produced more number of flowers in marigold (Tagetes erecta L.). The plants were grown in pot culture experiments and the largest flower diameter was produced in soil amended with $40 \%$ vermicompost. Further, the beneficial effect of vermicompost might be due to increased soil organic matter and improved physical properties of soil like bulk density and better aggregation. Edwards (1998) reported that vermicompost could promote early and vigorous growth of seedlings (Gopinathan and Prakash, 2014). Vermicompost has found to effectively enhance the root formation, elongation of stem and production of biomass, vegetables, ornamental plants etc. Also Chamani et al. (2008) studied the impact of vermicompost on the growth and flowering of Petunia hybrida 'Dream Neon Rose' in greenhouse conditions using 0, 20, 40 and $60 \%$ ratio of vermicompost and reported that vermicompost had positive, significant influence on the number of flower, leaf growth, and branch fresh and dry weights as compared to plants grown in vermicompost-lacking soil. Edwards and Burrows (1988) reported that vermicompost increased ornamental seedling emergence compared with those in control commercial plant growth media, using a wide range of test plants such as pea, lettuce, wheat, cabbage, tomato and radish however fertilizers are soil improvements applied to increase plant growth, the main nutrients added in fertilizer are nitrogen, phosphorus, potassium, other nutrients are added in small amounts. Fertilizers are required to bring out the best features of ornamental potted plants. For natural plants to grow and increase they need a number of chemical elements. Ashoorzadeh et al. (2016) found that vermicompost and NPK significantly improved the growth, yield and 
quality of rose flowers compared to control and that the improvement was greater when vermicompost and NPK fertilizers were mixed. Gangadharan and Gopinath (2000) reported that application of $10 \mathrm{t}$ of vermicompost $\mathrm{ha}^{-1}+80$ percent recommended NPK dose per ha for obtaining higher yield and net return per ha in Gladiolus spp. was successful. Also Amarjeet et al. (1996) recorded an increase of flower stalk height and leaf length in tuberose with an application of a higher dose of NPK and increased flowering period and the largest panicle length was produced with $200: 200: 400 \mathrm{~kg} / \mathrm{ha}$ NPK. In addition, they are eco-friendly, easily available and cost effective.

\section{Materials and Methods}

\section{Experimental Site}

The present experiment was carried out in the research and practice field of Siirt University Faculty of Agriculture, during the 2016-2017 vegetation periods (Figure 1).

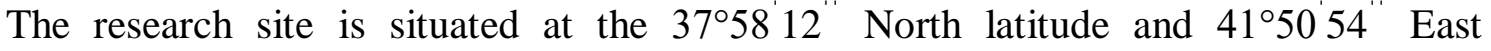
longitudes and at an altitude of 650 meters above sea level.

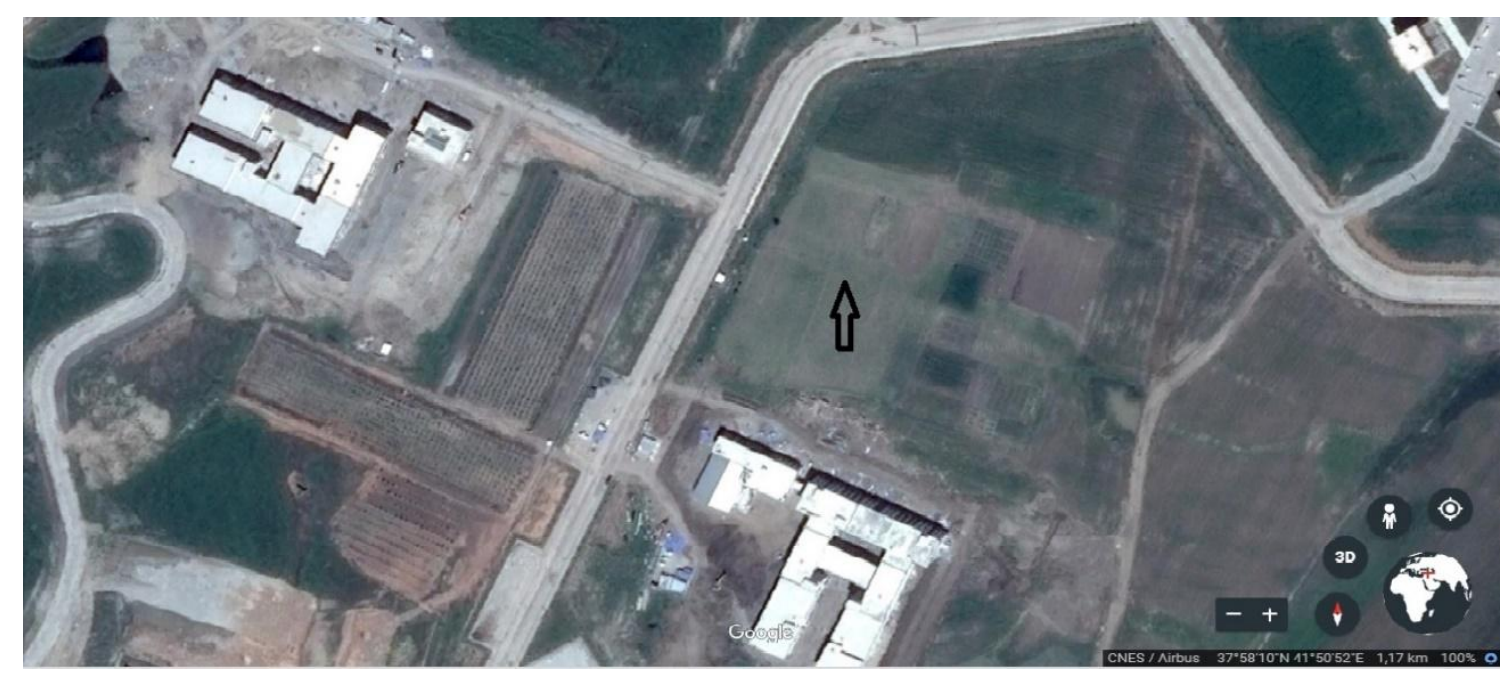

Figure 1. Location of sampling site (Google maps, 2018)

Siirt province has a semi-arid and subtropical climate with hot and dry summers, where maximum temperatures exceed $45^{\circ} \mathrm{C}$, the winters are cold and the minimum temperatures can reach as low as $5^{\circ} \mathrm{C}$ in December and January months. Some climatic properties were presented in Table 1.

The soil is categorized as sandy loam with low aggregation. The chemical composition of the soil collected from 0-30 cm depth before planting of Hyacinthus bulbs. Some soil properties were determined as clay for texture type, neutral for $\mathrm{pH}$, non-saline, medium lime, low for organic matter and phosphorus $\left(\mathrm{P}_{2} \mathrm{O}_{5}\right)$ and sufficient for potassium $\left(\mathrm{K}_{2} \mathrm{O}\right)$. 
Table 1. Some climatic values of the year where the experiment was carried out (Anonymous, 2017)

\begin{tabular}{l|c|c|c|c|c|c|c|c}
\hline Parameter & $\begin{array}{c}\text { November } \\
\mathbf{2 0 1 6}\end{array}$ & $\begin{array}{c}\text { December } \\
\mathbf{2 0 1 6}\end{array}$ & $\begin{array}{c}\text { January } \\
\mathbf{2 0 1 7}\end{array}$ & $\begin{array}{c}\text { February } \\
\mathbf{2 0 1 7}\end{array}$ & $\begin{array}{c}\text { March } \\
\mathbf{2 0 1 7}\end{array}$ & $\begin{array}{c}\text { April } \\
\mathbf{2 0 1 7}\end{array}$ & $\begin{array}{c}\text { May } \\
\mathbf{2 0 1 7}\end{array}$ & Average \\
\hline $\begin{array}{l}\text { Monthly avarege temperature } \\
\left({ }^{\circ} \mathrm{C}\right)\end{array}$ & 10.4 & 3.3 & 3.0 & 2.6 & 9.7 & 14.2 & 19.5 & 8.9 \\
$\begin{array}{l}\text { Monthly average of daily } \\
\text { max. temperatures }\left({ }^{\circ} \mathrm{C}\right)\end{array}$ & 16.45 & 7.2 & 7.4 & 7.9 & 14.8 & 20.0 & 25.1 & 14.1 \\
$\begin{array}{l}\text { Monthly average of daily } \\
\text { min. temperatures }\left({ }^{\circ} \mathrm{C}\right)\end{array}$ & 6 & 0.6 & -0.2 & -1.5 & 5.3 & 9.3 & 13.9 & 3.0 \\
$\begin{array}{l}\text { Average monthly 50 cm of } \\
\text { soil temperature }\left({ }^{\circ} \mathrm{C}\right)\end{array}$ & 15.6 & 8.6 & 6.6 & 5.9 & 10.1 & 14.5 & 19.4 & 11.5 \\
$\begin{array}{l}\text { Average monthly relative } \\
\text { humidity }(\%)\end{array}$ & 49.7 & 73.1 & 65.9 & 64.9 & 63.5 & 59.3 & 51.7 & 61.1 \\
$\begin{array}{l}\text { Average monthly total } \\
\text { precipitation (mm) }\end{array}$ & 55.6 & 121.4 & 49.4 & 45.6 & 118.8 & 149.9 & 74.8 & 87.9 \\
\hline
\end{tabular}

\section{Experimental Details}

This study was carried out with Hyacinthus orientalis L. cv. "Purple Star" as plant material. The experiment was laid out in a randomized block design with 7 treatments and three replicates including 12 bulbs per replicates. The plants were planted in November 2016, with solid worm fertilizer and 20:20:0 N:P:K fertilizer. The used solid worm fertilizer is obtained from Eisenia foetida culture worms known as red California worm produced by EkosolFarm producer company. Worm fertilizer dosages were used as 25 (V1), 50 (V2) and 75 (V3) g/plant on each bulb hole. 2 (NP1), 4 (NP2), and 8 (NP3) $\mathrm{kg} \mathrm{da}^{-1}$ dosages calculated from $\mathrm{N}$ and $\mathrm{P}_{2} \mathrm{O}_{5}$ containing inorganic fertilizer were applied. The fertilizers were given at the time of planting.

\section{Morphological Observations and Phenological Properties}

Some of the observations and measurements performed are shown in Figure 2.

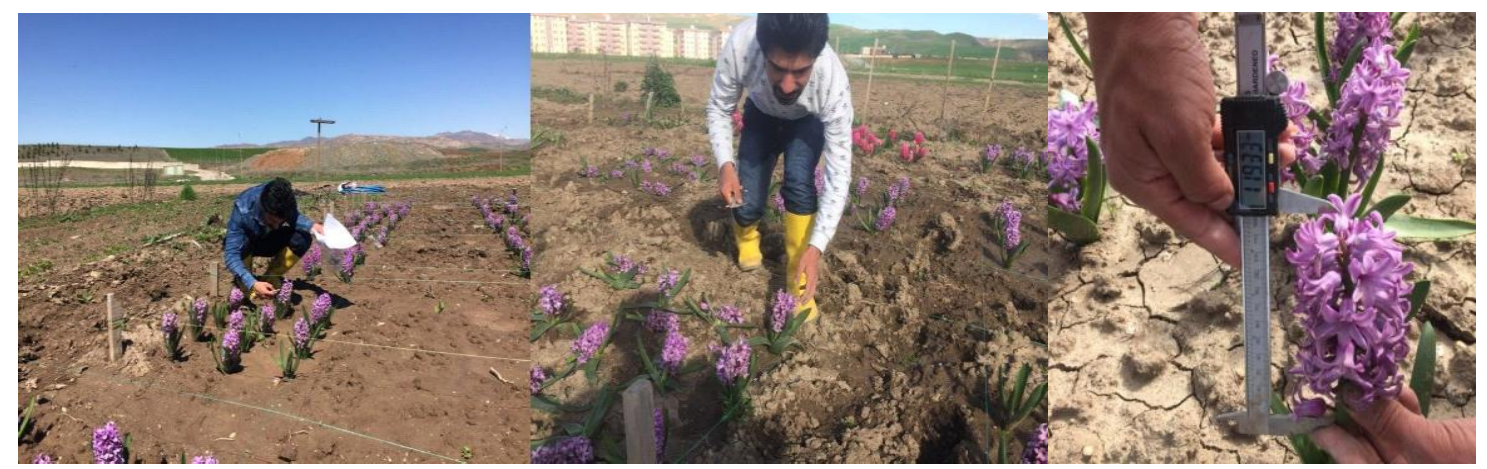

Figure 2. Hyacinths in experimental site 
First flowering time (day): The period taken for the opening of the floret was recorded from the date of spike initiation for the first florets opening.

Full flowering time (day): A number of days required for the full flowering time or the floret opening from the plantation moment to 50 percent sprouting of florets.

Harvest time (day): When the last 1-2 florets closed have been seen.

Leaf number/plant: A number of leaves per plant were counted at harvest time.

Leaf length ( $\mathrm{mm})$ : Leaf length was measured with digital compass.

Leaf diameter $(\mathrm{mm})$ : Leaf diameter was measured with digital compass.

Plant height (mm): Plant height was measured from the soil surface to the top of the plant.

Flower height $(\mathrm{mm})$ : The height of the flower was measured from the bottom floret to the top floret.

Flower diameter $(\mathrm{mm})$ : The width of the flower was measured for each flower.

Floret length $(\mathrm{mm})$ : The height of the floret was measured at full flowering time.

Floret diameter $(\mathrm{mm})$ : The diameter of floret was measured at full flowering time.

Floret number/flower: The number of florets per one flower was counted at full flowering time.

Stalk thickness $(\mathrm{mm})$ : The stalk thickness was measured at full flowering time.

\section{Statistical Calculations}

Data were analyzed by the analysis of variance method for two-factor randomized block design, by SAS 9.1 Statistical Package Program. The LSD multiple comparison test was used to compare the averages. Tests were conducted at $\alpha=0.05$ significance level (Düzgüneş et al., 1987). Descriptive statistics, like mean and standard errors, were presented for the investigated features.

\section{Results and Discussions}

The results of the present investigation related to the impact of NP fertilizers and worm fertilizer treatments, mainly on growth and floral parameters are explained in this section. The effects of all fertilizer types on parameters were not found statistically significant. The data of the final observations of the various parameters during growth and flowering period were subjected to statistical analysis and the results have been presented through tables and suitable diagrams.

Table 2. Effects of NP and worm fertilizers dosages on growth and floral parameters

\begin{tabular}{|c|c|c|c|c|c|c|c|c|c|c|c|c|c|}
\hline 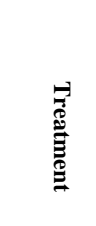 & & 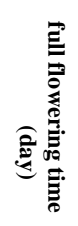 & 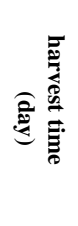 & $\widehat{\underline{E}}$ & 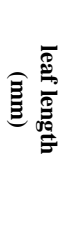 & 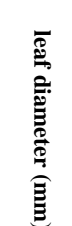 & 茣 & & 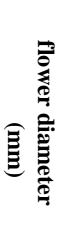 & 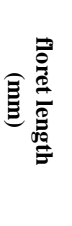 & 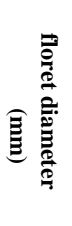 & 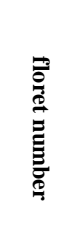 & 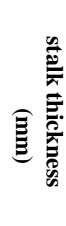 \\
\hline Control & 136.35 & 138.38 & 140.92 & 5.54 & 118.88 & 26.30 & 165.28 & 103.16 & 63.92 & 24.08 & 26.79 & 35.91 & 12.34 \\
\hline V1 & 135.25 & 136.54 & 137.70 & 5.71 & 128.28 & 27.63 & 174.38 & 115.83 & 64.63 & 25.33 & 28.14 & 32.14 & 13.50 \\
\hline V2 & 136.17 & 137.59 & 139.35 & 5.62 & 121.34 & 27.17 & 177.99 & 112.57 & 66.96 & 25.10 & 26.49 & 35.91 & 12.61 \\
\hline V3 & 135.67 & 137.11 & 138.67 & 5.41 & 126.03 & 26.52 & 178.36 & 116.33 & 60.72 & 26.25 & 25.69 & 33.80 & 12.79 \\
\hline NP1 & 135.90 & 137.38 & 139.55 & 5.38 & 127.52 & 28.31 & 175.02 & 115.17 & 64.48 & 25.21 & 26.48 & 37.69 & 13.35 \\
\hline NP2 & 135.34 & 136.61 & 138.33 & 5.54 & 127.18 & 26.46 & 176.09 & 114.24 & 66.94 & 26.76 & 26.90 & 36.64 & 12.89 \\
\hline NP3 & 136.15 & 137.73 & 138.55 & 5.66 & 123.27 & 28.86 & 179.54 & 111.39 & 61.80 & 25.42 & 26.17 & 34.37 & 12.62 \\
\hline
\end{tabular}




\section{Phenological Observations}

\section{First flowering time (day)}

The data regarding days to first flowering time are presented in Table 2. No significant difference was observed in the case of first floret opening of hyacinth. The first floret opening was the earliest (135.25 days) in V1 which was closely followed by V3 and NP2 (Figure 3a). The control plants took the maximum days (136.35) which was followed by other treatment for the first floret open. Sönmez et al. (2013) showed that the lowest number of days to primary candle formation were 116 days, the lowest number of days to mature flower formation were 117 days, the lowest number of days to harvest were 121 days, the lowest number of days to primary candle formation were 123 days, in the case of gladioli plant. Sharma et al. (2003) observed that on onion growth. In the study, flowering and bulb production attributes of tuberose were recorded that among the different nitrogen dosages minimum time for sprouting were 14.74 days, which was recorded with the application of $300 \mathrm{~kg} \mathrm{~N} / \mathrm{ha}$ whereas maximum time for the sprouting of bulbs (21.57 days) was recorded in control. Early sprouting in tuberose with higher doses of nitrogen, phosphorus, and their interaction might be due to the stimulation of bulbs by comparatively high nutrient availability ( $\mathrm{N}$ and $\mathrm{P}$ ) and their respective absorption through bulbs surface and primary roots. Keisam et al. (2014) observed that first flowering time of gladioli was greatly influenced by different combinations of organic and inorganic fertilizers.

\section{Full Flowering Time (day)}

The data concerning the days taken to full flowering time, as influenced by different treatments were presented in Table 2. Statistically no significant difference was observed in the case of full flowering time (days) of hyacinth by different levels of NP and worm fertilizers. However, it can be revealed that days to the full flowering time was the earliest (136.54 days) in V1 which was closely followed NP2 and other treatments (Figure $3 b$ ). Full flowering took the longest (138.38 days) for the control plant. However, Rajadurai and Beaulah (2000) also found that increasing levels of NPK fertilizers resulted in the full flowering of African marigold, which also brought about full flowering, contains essential plant nutrients like $\mathrm{N}, \mathrm{P}, \mathrm{K}, \mathrm{Ca}, \mathrm{Fe}, \mathrm{S}, \mathrm{Mg}, \mathrm{Zn}, \mathrm{Mo}$, $\mathrm{Cu}, \mathrm{Mn}, \mathrm{Co}$ and $\mathrm{B}$ in a balanced amount in addition to organic fertilizers, which gave rise to full flowering.

\section{Harvest time (day)}

The data belonging to days taken to harvest time, as influenced by different treatments were presented in Table 2 and Figure 3c. No significant difference was observed in the case of harvest time (day) of hyacinth by different levels of NP fertilizers and worm fertilizer. However, it can be revealed that days to the harvest time was the earliest (137.70 days) in V1 which was closely followed NP2 and other treatments. Harvest time took the longest time (140.92 days), for the control plants (Figure 3c).

Similar results were also found by Chakkaborty et al. (2009). On the other hand, manure brought about the late flowering of marigold in 78.3 days i.e. 94.8 days later than in the case of worm fertilizer. The flowering period was also maximsed (up to 24.51 days) due to application of worm fertilizer. This could have arisen from differences in their 


$$
\text { - } 3879 \text { - }
$$

source and nutrients composition as well as timing of nutrients availability to the flowering plants.

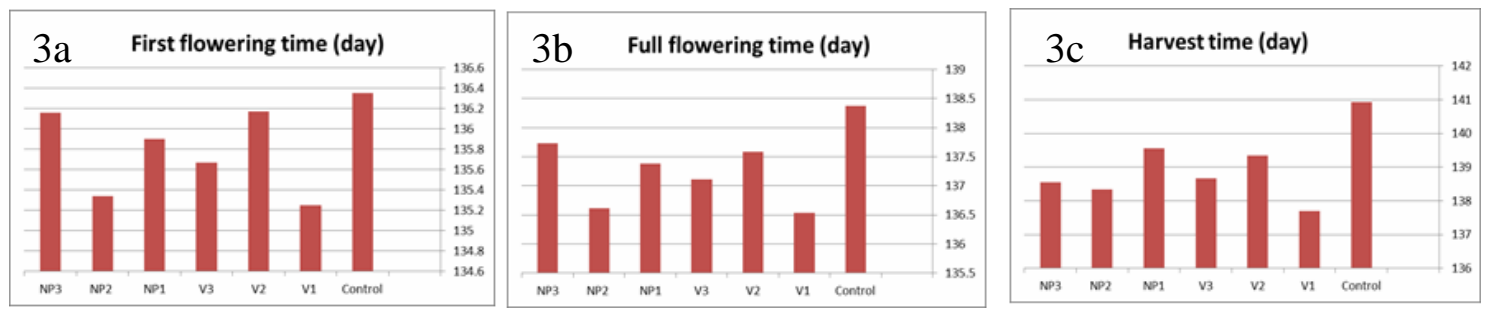

Figure 3. Phenological properties a-First flowering, b-Full flowering, c-Harvest times (day)

\section{Morphological Properties}

\section{Leaf number}

Leaf number was counted and no significant difference was found due to different levels of NP and worm fertilizer presented in Table 2. Leaf number varied from 5.41 to 5.71 per plant. The maximum number of leaf (5.71) was recorded with the V1 treatment. Results reveal Figure $4 a$ that the increasing level of NP increasing the leaf number of hyacinth. And that is the increasing level of worm fertilizer decreased the leaves number of hyacinth. It was not a significant result because a maximum number of leaves was recorded in V1 and followed by other treatment. This result is in agreement with the findings of El-Desuki et al. (2006). They observed that nitrogen application had no significant effect on leaf number of onion. Also Sultana et al. (2015a) observed that number of leaf/plant of summer onion was found insignificant when the influence of integrated $\mathrm{N}$ from urea, cow dung, and worm fertilizer was compared. The highest number of leaves/plant (6.00) was observed after the treatment with $120 \mathrm{~kg} \mathrm{~N} / \mathrm{ha}$ supplied from urea followed by other treatments. Alternatively, the minimum number of leaves (4.98) per plant was found in control plots, where no fertilizer was applied. Also Keisam et al. (2014) observed that leaf number of gladioli was greatly influenced by different combinations of organic and inorganic fertilizers. The highest number of leaves (5.60) was obtained from the mixture consisting of vermicompost $\left(2.5 \mathrm{t} \mathrm{ha}^{-1}\right)+$ humic acid $(0.2 \%)+$ Vesicular Arbuscular Mycorrhiza.

\section{Leaf length $(\mathrm{mm})$}

Leaf length of hyacinth varied from $118.88 \mathrm{~mm}$ to $128.28 \mathrm{~mm}$ over the treatments (Table 2). The leaf length (128.28) was recorded with V1 which was closely followed by NP1 and NP2 and V3. The minimum leaf length $(118.88 \mathrm{~mm})$ was produced from the control treatment. Results reveal (Figure $4 b$ ) that the increasing level of NP decreased the leaf height of hyacinth. However, the best performance was recorded in the leaf height with V1. On the other hand, Sönmez et al. (2013) observed that the highest leaf length $(47.9 \mathrm{~cm})$, the highest plant length $(70.6 \mathrm{~cm})$, and the highest leaf length $30.78 \mathrm{~mm}$ ) was obtained in waste mushroom compost application, in the case of gladioli plant. Sultana et al. (2015b) observed that the results showed that the rate of effects within NPK fertilizers and worm fertilizer treatments were not found significant on leaf length of (Zinnia elegans) flowers. However, Keisam et al. (2014) observed that leaf length of gladioli was greatly influenced by different combinations of organic and inorganic fertilizers. The 
highest leaf length $(50.03 \mathrm{~cm})$ was obtained from the mixture consisting of vermicompost (2.5 t ha-1) + humic acid (0.2\%) + Vesicular Arbuscular Mycorrhiza.

\section{Leaf diameter $(\mathrm{mm})$}

Leaf diameter of hyacinth varied from $26.30 \mathrm{~mm}$ to $28.86 \mathrm{~mm}$ over the treatments (Table 2). The widest leaf $(28.86 \mathrm{~mm})$ was recorded with NP3 which was followed by and statistically similar with NP1 and V1 and V2 (Figure 4c). The narrowest leaf $(26,30$ $\mathrm{mm}$ ) was produced from the control closely followed by other treatments. There was no significant difference. Sönmez et al. (2013) observed that the highest leaf length (47.9 $\mathrm{cm})$, the highest plant length $(70.6 \mathrm{~cm})$. While the highest leaf diameter $(30.78 \mathrm{~mm})$ was obtained in waste mushroom compost application on gladioli plant. Keisam et al. (2014) observed that leaf width of gladioli was greatly influenced by different combinations of organic and inorganic fertilizers. The highest leaf width $(8.62 \mathrm{~cm})$ was determined on the mixture consisting of vermicompost $(2.5 \mathrm{t}$ ha-1) + humic acid $(0.2 \%)+$ Vesicular Arbuscular Mycorrhiza.

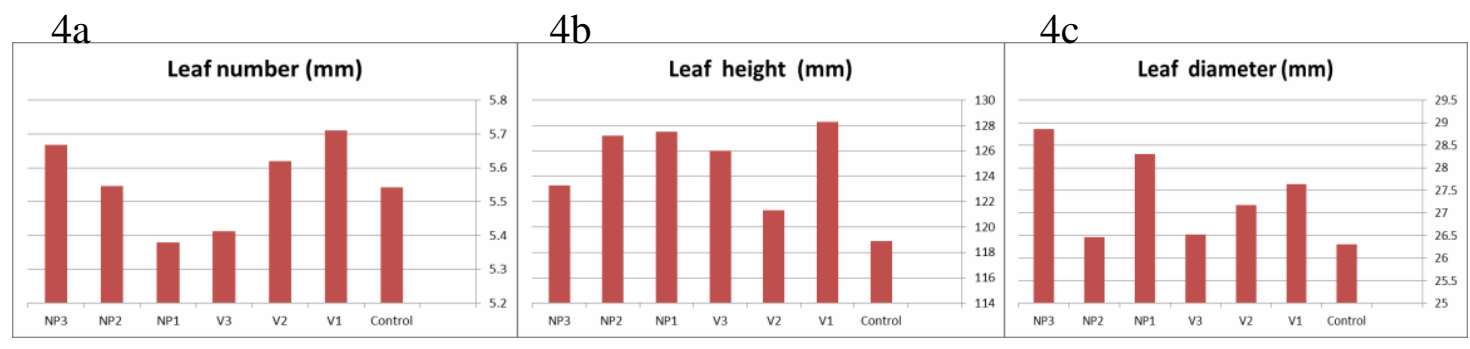

Figure 4. Under treatments a-Leaf number, b-Leaf length, c-Leaf diameter ( $\mathrm{mm})$

\section{Plant height ( $\mathrm{mm})$}

Plant height of hyacinth was measured on flowering. It was observed that plant height was not significantly influenced by different levels of NP and worm fertilizer application (Table 2). The tallest plant $(179.54 \mathrm{~mm})$ was recorded in NP3, which was followed by and statistically similar to other treatment. The shortest plant $(165.28 \mathrm{~mm})$ was found in control. No significant difference was found proving that the increasing level of NP are increasing the plant height of $H$. orientalis and that the increasing level of worm fertilizer increases the plant height of hyacinth (Figure 5a). El-Desuki et al. (2006) stated that plant height of onion increased with increasing rates of $\mathrm{N}$ up to 125 $\mathrm{kg} / \mathrm{ha}$ and decreased thereafter. Also, Sultana et al. (2015b) observed that the impact of NPK fertilizers on the shoot heights of Zinnia plant was found similar with that of control. Shoot heights of plant increased with the rates of vermicompost application but the values obtained in the $10 \%$ and $20 \%$ were not significantly different.

\section{Flower height $(\mathrm{mm})$}

A noticeable variation in the flower height was recorded due to application of different levels of NP and worm fertilizer presented in Table 2. The longest flower $(116.33 \mathrm{~mm})$ was measured with V3, which was statistically similar with that of NP1, $\mathrm{V} 1$, and V2 and other treatment. The shortest flower $(103.16 \mathrm{~mm})$ was produced with control. Results revealed (Figure $5 b$ ) that the increasing level of NP decreased the flower height of hyacinth and that the increasing level of worm fertilizer increased the flower height of hyacinth. A similar result was found that soil application of fertilizer increased 


$$
-3881-
$$

flowering branch length as compared to its foliar application and no-fertilization on gladioli plant (Mohammadi et al., 2014). Turkoglu et al. (2008) observed that flower height of narcissi plants as $18.38 \mathrm{~mm}$.

\section{Flower diameter ( $\mathrm{mm})$}

Flower diameter was not significantly influenced by different levels of NP and worm fertilizer supplement (Table 2). The highest flower diameter of $66.96 \mathrm{~mm}$ was found in plants grown under V2 which was closely followed by NP2, V1, NP1 and other treatments. The lowest flower diameter $(60.72 \mathrm{~mm})$ was recorded with the V3 closely flowed by control (Figure 5c). On the other hand, Mohammadi et al. (2014) found that soil application of fertilizer increased flower diameter compared to its foliar application and no-fertilization on gladioli plant.

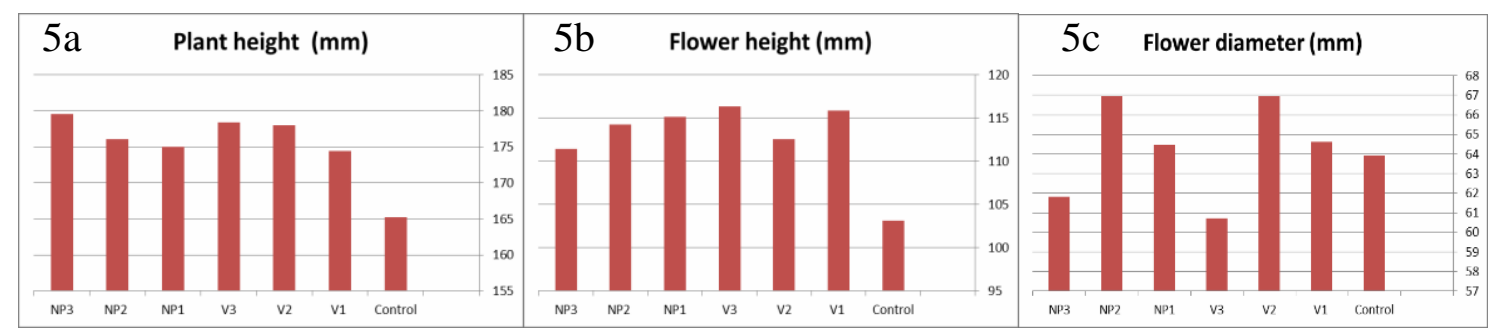

Figure 5. Under treatments a-Plant height, $b$ - Flower height, c-Flower diameter (mm)

\section{Floret length $(\mathrm{mm})$}

Floret length of hyacinth was measured after full flowering time. It was observed that floret length was not significantly influenced by different levels of NP and worm fertilizer application (Table 2.). The highest floret length $(26.76 \mathrm{~mm})$ was recorded in NP2 which was followed by and statistically similar with other treatment without control, and the lowest floret length $(24.08 \mathrm{~mm})$ was found in control. Results revealed (Figure 6a) that the increasing level of NP2, increased the floret height but increasing level of NP3, decreased the floret length of $H$. orientalis and that the increasing level of $\mathrm{V} 2$, decreased the floret height but increasing level of V3, not significantly increased the floret height of hyacinth.

\section{Floret diameter ( $\mathrm{mm})$}

Floret diameter was not significantly influenced by different levels of NP and worm fertilizer is presented in Table 2. The highest floret diameter $(28.14 \mathrm{~mm})$ was found in plants grown under V1, which was closely followed by other treatment except for V3. The lowest floret diameter $(25.69 \mathrm{~mm})$ was recorded with the V3. Results revealed (Figure $6 b$ ) that the increasing level of NP2, increased the floret diameter but increasing level of NP3, decreased floret diameter of hyacinth flower. And the increasing level of worm fertilizer do not increase the floret diameter of hyacinth.

\section{Floret number/flower}

Floret number was counted and no significant variation was found due to different levels of NP and worm fertilizer is presented in Table 2. Floret number varied from 32.14 to 37.69 per plant. The maximum number of floret (37.69) was recorded with the NP1. The lowest 
number of floret per plant was noted with the V1, (32.14) closely followed by NP3, V3 (Figure 6c). Similar results were recorded by Sultana et al. (2015b). The rate of the effect of NP fertilizers was not found significant in the production of flowers of Zinnia plant. Also, Mohammadi et al. (2014) found that soil application of fertilizer increased flower number compared to its foliar application and no-fertilization in the case of gladioli. A similar result Senthilkumar et al. (2004) concluded that the appropriate ratio application of worm fertilizer resulted in higher bud number, flower number, shoot weight, root weight and plant height, which is in agreement with our study.

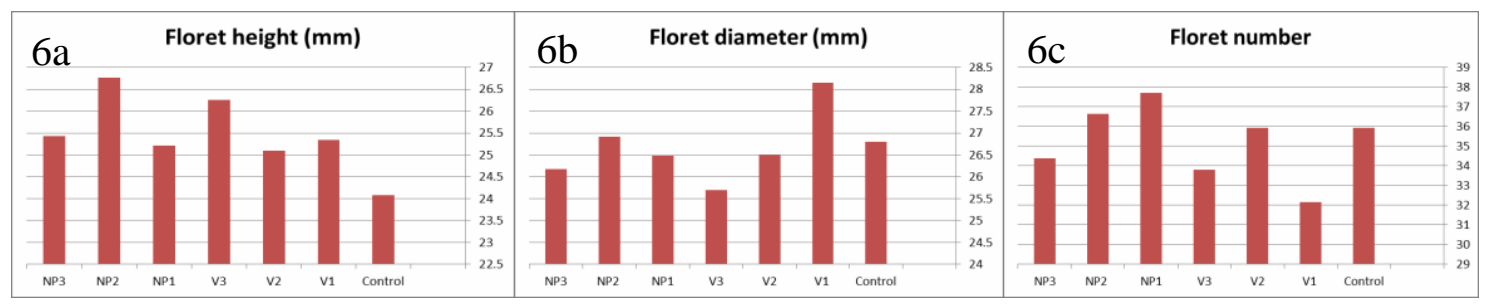

Figure 6. Under treatments a-Floret height, $b$-Flower diameter (mm), c-Flower number

\section{Stalk thickness ( $\mathrm{mm}$ )}

Stalk thickness for hyacinth was not significantly influenced by different levels of NP and worm fertilizer supplement (Table 2). The highest stalk thickness of $13.50 \mathrm{~mm}$ was found in plants grown under V1. The lowest stalk thickness of $12.34 \mathrm{~mm}$ was recorded with the control and closely followed by other treatment except for V1, NP1. It is presented that the increasing level of NP decreased the stalk thickness of plants (Figure 7). Also, Turkoglu et al. (2008) observed $5.56 \mathrm{~mm}$ of stalk thickness in the case of narcissi plant. Padem and Alan (1995) observed that combined NPK applications may elevate the nitrogen, potassium and phosphorus contents and the increase in stalk length might be due to elevated levels of macronutrients which have a positive effect on floral characteristics of tomatoes.

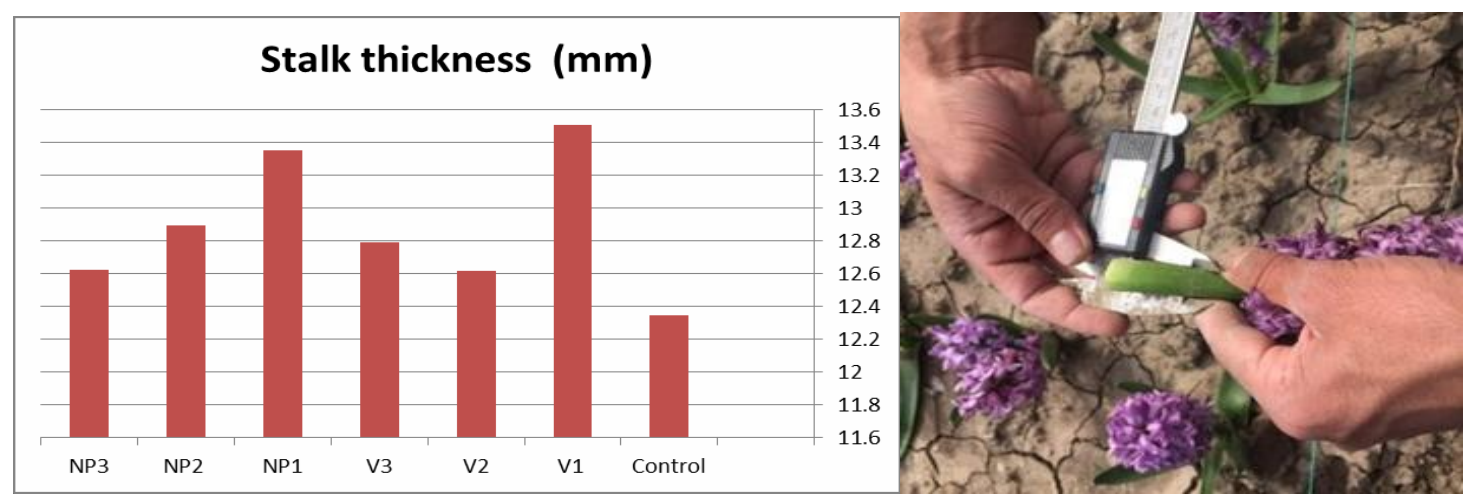

Figure 7. Under treatments stalk thickness ( $\mathrm{mm})$

\section{Conclusions}

In this present study concerning the effects of dosages of worm fertilizer and nitrogen-phosphorus fertilizer on plant growth of hyacinth (Hyacinthus orientalis L. cv. "Purple Star") in ecological conditions of Siirt was investigated. It is known that 
chemical fertilization has negative effects when it is used unconsciously and in excess, by mixing with soil and water. Since aesthetics are important in ornamental plants, it is considered that the best performance of the flower criteria is possible with fertilization and excessive chemical fertilization is carried out if necessary. However, the same effect can be made without harming the environment. In Siirt province there is no commercial production in terms of cut flowers, bulbous ornamental plants, indoor or outdoor ornamental plants. However, due to its climate structure, Siirt province is suitable for growing many ornamental plants. According to this study, worm fertilizer, which is new for Turkey not known or used in Siirt province yet, has positive effects on the flowering bulbous ornamental plants to encourage especially hyacinth growing. As a result, for some plant growing and flower criteria, worm fertilizer can be used instead of chemical fertilizer.

Acknowledgements. This study is a part of Ms. thesis and is supported with the project no 2016SIÜFEB-29 by Siirt University Coordinator of Scientific Research and Projects.

\section{REFERENCES}

[1] Amarjeet, S, Godara, N. R., Ashok, K., Singh, A., Kumar, A. (1996): Effect of N.P.K on flowering and flower quality of tuberose (Polianthes tuberosa L.) cv. Single. - Haryana Agric. Univ. J. Res. 26(1): 43-49.

[2] Anonymous (2017): T.C. Orman ve Su İşleri Bakanlığı. Meteoroloji Genel Müdürlüğü Meteoroloji 15. Bölge Müdürlüğü. http://www.diyarbakir.mgm.gov.tr/

[3] Google maps. Acces date: 13.05.2018 https://www.google.com.tr/maps/@37.9678476,41.8461517,1172m/data=!3m1!1e3

[4] Arancon, N. Q., Edwards, C. A. (2005): Effects of vermicomposts on plant growth. International Symposium Workshop on Vermi Technologies for Developing Countries (ISWVT 2005), Los Banos, Philippines.

[5] Ashoorzadeh, H., Mohammadi, T. A., Mahboub, K. A. (2016): Choose a planting substrate and fertilization method to achieve optimal growth of Araucaria excelsa. Journal of Ornamental Plants 6(3): 201-215.

[6] Chakkaborty, S., Sadhukhan, R., Dey, S. (2009): Integrated nutrient management studies in Anthurium. - Journal of Ornamental Horticulture 12(4): 265-268.

[7] Chamani, E., Joyce, D. C., Reihanytabar, A. (2008): Vermicompost effects on the growth and flowering of Petunia hybrida 'Dream Neon Rose'. - American-Eurasian Journal of Agricultural and Environmental Sciences 3(3): 506-512.

[8] Darlington, C. D., Hair, J. B., Hurcombe, R. (1951): The history of the garden hyacinths. - Heredity 5: 233-252.

[9] Düzgüneş, N., Allen, T. M., Fedor, J., Papahadjopoulos, D. (1987): Lipid mixing during membrane aggregation and fusion: why fusion assays disagree. - Biochemistry 26(25): 8435-8442.

[10] Edwards, C. A. (1998): Use of earthworms in breadown and management of organicwastes. - In: Edwards, C. A. (Ed.) Earthworm ecology. CRC Press LLC, Boca Raton, Florida, 327-354.

[11] Edwards, C. A., Burrows, I. (1988): The potential of earthworm composts as plant growth media. - In: Edwards, C.A. and Neuhauser, E.F. (Eds.) Earthworms in Waste and Environmental Management, SPB Academic Publishing, The Hague, 211-219.

[12] El-Desuki, M., Abdel-Mouty, M. M., Ali, A. H. (2006): Response of onion plants to additional dose of potassium application. - Journal of Applied Science Research 2(9): 592-597. 
[13] Gangadharan, G. D., Gopinath, G. (2000): Effect of organic and inorganic fertilizers on growth, flowering and quality of Gladiolus cv. White Prosperity. - Karnataka J. Agric. Sci. 13(2): 401-405.

[14] Gopinathan, R., Prakash, M. (2014): Effect of vermicompost enriched with bio-fertilizers on the productivity of tomato (Lycopersicum esculentum Mill.). - Int. J. Curr. Microbiol. App. Sci. 3(9): 1238-1245.

[15] Hu, F. R., Liu, H. H., Wang, F., Bao, R. L., Liu, G. X. (2015): Root tip chromosome karyotype analysis of hyacinth cultivars. - Genet. Mol. Res. 14: 10863-10876.

[16] Keisam, P., Manivannan, K., Kumar, S. R. (2014): Effect of organic nutrients on growth, flowering and yield of Gladiolus grandiflorus L. - Asian Journal of Horticulture 9 (2): 416- 420.

[17] Khan, A., Ishaq, F. (2011): Chemical nutrient analysis of different composts (vermicompost and pitcompost) and their effect on the growth of a vegetative crop Pisum sativum. - Asian Journal of Plant Science and Research 1: 116-130.

[18] Mohammadi, T. A., Deljoi, T. T., Hashemabadi, D., Kaviani, B. (2014): Effect of different substrates and fertilization methods on growth and yield daisy. - Journal of Greenhouse Culture Science and Technology 20(5): 95-109. (In Persian).

[19] Padem, H., Alan, R. (1995): The effect of foliar fertilizers on yield, chlorophyll and chemical content of lettuce (Lactuca sativa L.). - Atatürk Univ. J. Agric. Fac. 26: 21-34.

[20] Rajadurai, K. R., Beaulah, A. (2000): The effect of inorganic fertilizers, Azospirillum and VAM on yield characters of African marigold (Tagetes erecta). - Journal of Ecotoxicology \& Environmental Monitoring 10(2): 101-105.

[21] Sangwan, P., Garg, V. K., Kaushik, C. P. (2010): Growth and yield response of marigold to potting media containing vermicompost produced from different wastes. Environmentalist 30(2): 123-130.

[22] Senthilkumar, S., Sriramachandrasekharan, M. V., Haripriya, K. (2004): Effect of vermicompost and fertilizer on the growth and yield of rose. - J. Interacademicia 8: 207210.

[23] Sharma, R. P., Datt, N., Sharma, P. K. (2003): Combined application of nitrogen, phosphorus, potassium and farmyard manure in onion (Allium cepa) under high hills, dry temperate conditions of north-western Himalayas. - Indian Journal of Agricultural Science 73(4): 225-227.

[24] Shen, Q., Wang, H., Zhu, H. X., Gu, J. J. (2004): Tulips and Hyacintis. - China Forestry Press, Beijing, 63-64.

[25] Smigielska, M., Jerzy, M., Krzymińska, A. (2014): The growth and flowering of Hyacinthus orientalis $\mathrm{L}$. forced in pots under fluorescent light of different colours. - Acta Agrobotanica 67(3): 75-82.

[26] Sönmez, F., Çı̆̆g, A., Gülser, F., Başdoğan, G. (2013): The effects of some organic fertilizers on nutrient contents in hybrid Gladiolus. - Eurasian Journal of Soil Science (EJSS) 2(2): 140-144.

[27] Sultana, S., Paul, A. K., Sultana, D., Sarker, J. R. (2015a): Influence of integrated organic- inorganic nitrogen on growth and nutrient concentration of summer onion (Allium cepa). - Bangladesh Journal of Agricultural Research 39(3): 529-545.

[28] Sultana, S., Kashem, M. A., Mollah, A. K. (2015b): Comparative assessment of cow manure vermicompost and NPK fertilizers and on the growth and production of zinnia (Zinnia elegans) flower. - Open Journal of Soil Science 5(9): 193.

[29] Turkoglu, N., Alp, S., Cig, A. (2008): Effect of Diamonium Phosphate (DAP) fertilization in different doses on bulb and flower of Narcissus. - American-Eurasian J. Agric. \& Environ. Sci. 4(5): 595-598. 